\title{
Expression profile analysis of the inflammatory response regulated by hepatocyte nuclear factor $4 \alpha$
}

\author{
Zhongyan Wang ${ }^{1}$, Eric P Bishop ${ }^{2}$, Peter A Burke ${ }^{1 *}$
}

\begin{abstract}
Background: Hepatocyte nuclear factor $4 \alpha(H N F 4 \alpha)$, a liver-specific transcription factor, plays a significant role in liver-specific functions. However, its functions are poorly understood in the regulation of the inflammatory response. In order to obtain a genomic view of HNF4 $\alpha$ in this context, microarray analysis was used to probe the expression profile of an inflammatory response induced by cytokine stimulation in a model of HNF4a knock-down in HepG2 cells.

Results: The expression of over five thousand genes in HepG2 cells is significantly changed with the dramatic reduction of HNF4 $\alpha$ concentration compared to the cells with native levels of HNF4 $\alpha$. Over two thirds (71\%) of genes that exhibit differential expression in response to cytokine treatment also reveal differential expression in response to HNF4 $\alpha$ knock-down. In addition, we found that a number of HNF4 $\alpha$ target genes may be indirectly mediated by an ETS-domain transcription factor ELK1, a nuclear target of mitogen-activated protein kinase (MAPK).

Conclusion: The results indicate that HNF4 $\alpha$ has an extensive impact on the regulation of a large number of the liver-specific genes. HNF4 $\alpha$ may play a role in regulating the cytokine-induced inflammatory response. This study presents a novel function for HNF $4 \alpha$, acting not only as a global player in many cellular processes, but also as one of the components of inflammatory response in the liver.
\end{abstract}

\section{Background}

Hepatocyte nuclear factor $4 \alpha(\mathrm{HNF} 4 \alpha)$ is a highly conserved member of the nuclear receptor superfamily. It is highly expressed in liver, kidney, intestine, and pancreas in mammals. The active form of HNF4 $\alpha$ is a homodimer which recognizes a direct repeat (DR) of the AGGTCA motif separated by 1 nucleotide (DR1) as a binding site. HNF4 $\alpha$ exerts direct transcriptional effects on target genes, and it also works indirectly via the positive regulation and negative regulation of other liver-enriched transcription factors, each of which regulates numerous downstream targets [1,2]. In contrast to the liver-enriched transcription factors HNF1 $\alpha, \mathrm{HNF} 3 \alpha$, HNF6, and CAAT/enhancer-binding protein (C/EBP) $\alpha$, which when disrupted in the mouse genome the mice are viable but show specific effects on hepatocyte differentiation, metabolic function, and gene expression [3-6], disruption of the mouse HNF4a gene is embryonic

\footnotetext{
* Correspondence: peter.burke@bmc.org

'Department of Surgery, Boston University School of Medicine, Boston, Massachusetts 02118, USA

Full list of author information is available at the end of the article
}

lethal [7]. Studies with HNF4 $\alpha$ deficient mice [8] have established the critical role of this factor in regulating diverse liver functions, including glucose, fatty acid and cholesterol homeostasis, bile acid and urea biosynthesis [9-11]. Defects in HNF4 $\alpha$ function have been linked to the human disease maturity onset diabetes of the young 1(MODY1) that results from haploinsufficiency of HNF4a gene [12]. The pivotal role of HNF4 $\alpha$ in the maintenance of the differentiated hepatic phenotype is highlighted by the exceptionally high number of potential target genes revealed by genome-scale target search studies. Binding sites for HNF4 $\alpha$ in genes expressed in the liver occur more frequently than those of other liver-enriched transcription factors [13], supporting the idea that HNF4 $\alpha$ is a global regulator of liver gene expression.

Diverse signaling pathways regulate the transcription of hepatocyte-specific genes. For example, trauma or infection results in the release of proinflammatory cytokines, e.g., interleukin (IL)-6, IL-1, and tumor necrosis factor- $\alpha$ (TNF- $\alpha)$. The release of these cytokines has long been known to stimulate the acute phase response 
(APR) and rapidly alters rates of synthesis of a group of plasma proteins known as acute phase proteins (APPs) [14]. APPs are an established diagnostic tool as early indicators of inflammation and disease. Many APPs play beneficial roles in mediating the complex inflammatory response and seeking to restore homeostasis, but prolonged exposure to acute phase conditions has been correlated with inflammatory syndromes such as sepsis and multiple organ failure $[15,16]$. An understanding of the molecular events that are involved in mediating the response to external stresses can lead to the development of therapeutic strategies for preventing the progression of the APR to the chronic inflammatory states, while preserving its protective effects.

APP gene expression is regulated at the level of transcription. Transcriptional activation is mediated by a number of transcription factors. Beyond the well-known nuclear factor $-\kappa \mathrm{B},(\mathrm{NF}-\kappa \mathrm{B})$ and signal transducer and activator of transcription (STAT) family members, HNF4 $\alpha$ has been shown to be involved in the regulation of liver-specific genes, including acute phase genes $[17,18]$. It has been reported that in several injury models, injury leads to significant changes in binding activities of several liver-enriched transcription factors, including HNF4 $\alpha$ [18-20]. However, the functional analysis of HNF4 $\alpha$ regulated-APR genes so far has mainly relied on the description of the expression level of a few selected genes [21]. To achieve a global view of HNF4 $\alpha$ during the APR, we used microarray analysis to evaluate the expression profile in HepG2 cell, a human hepatoma cell line. This cell line is similar to hepatocytes in terms of biologic responsiveness [22-24] and is widely used as a model system for studying the regulation of acute phase protein synthesis in human liver [25-27]. In this study, HepG2 cells were treated with either HNF4 $\alpha$ short hairpin RNA (shRNA) or cytokines (IL-6, IL-1 $\beta$, TNF- $\alpha$ ) alone, or in combination of the two treatments. Our results demonstrate that $\mathrm{HNF} 4 \alpha$ is an important regulator in liver gene expression. The highly significant overlap of genes sensitive to HNF $4 \alpha$ knock-down and cytokine treatment suggests that HNF $4 \alpha$ may be involved in the regulation of the liver's inflammatory response. Our data also show that HNF4 $\alpha$ may mediate a certain amount of genes indirectly via the ETSdomain transcription factor ELK1, a mitogen-activated protein kinase (MAPK)-responsive transcription factor $[28,29]$, which is a previous undefined mechanism for $\mathrm{HNF} 4 \alpha$ regulation.

\section{Results and discussion}

\section{Knock-down endogenous HNF4 $\alpha$ in HepG2 cells}

To study the role of HNF4 $\alpha$ in liver-specific gene expression and the inflammatory response, the endogenous HNF4 $\alpha$ in HepG 2 cells was knocked down by the technique of RNA interference. As shown in Figure 1, HNF $4 \alpha$ shRNA caused a reduction in mRNA and protein levels of HNF $4 \alpha$ by more than $70 \%$ relative to control levels assayed by real-time PCR and Western blot. Our results indicate that $\mathrm{HNF} 4 \alpha$ shRNA can efficiently and specifically knock-down HNF4 $\alpha$ in HepG2 cells [21].

\section{HNF4 $\alpha$ acts as a global regulator of liver-specific gene expression}

Given that HNF4 $\alpha$ is a central mediator in hepatocytespecific gene expression and liver function, it is important to identify the full spectrum of genes impacted by the loss of HNF4 $\alpha$. To reach this end, microarray analysis was performed to probe differences in gene expression between the control and HNF4 $\alpha$ knock-down HepG2 cells. Because we are particularly interested in how HNF4 $\alpha$ alters global gene expression patterns during the inflammatory response, we also examined gene expression in response to the inflammatory response induced by cytokine treatment.

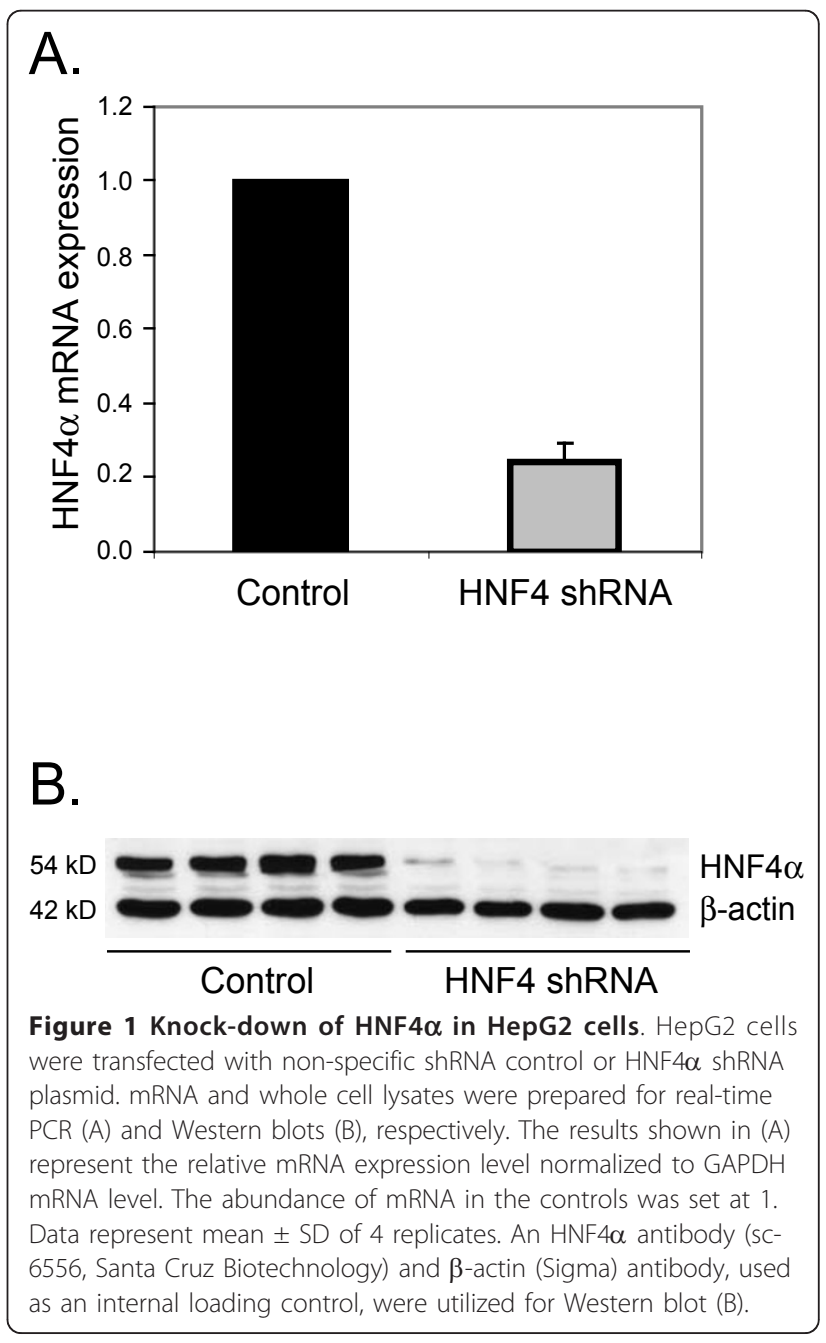


A two-way ANOVA was performed to identify differentially expressed genes and classify the observed expression patterns. This procedure identifies genes with altered expression in response to HNF4 $\alpha$ shRNA or cytokines alone, or in combination HNF4 $\alpha$ knockdown with cytokine treatments. The entire dataset is available at the NCBI Gene Expression Omnibus http:// www.ncbi.nlm.nih.gov/geo/ with the accession number GSE15991. From this analysis, a total of 14,220 unique probesets were found to be present in the samples. Two-way ANOVA analysis was then used to determine which probesets were differentially expressed between the untreated control and treated groups. The ANOVA analysis identified four categories of interest (Figure 2): Category A, "HNF4 $\alpha$ shRNA only" contains genes that are significantly regulated by HNF4 $\alpha$ shRNA, but not by cytokines; Category B, "Cytokine only" contains genes that respond to cytokine treatment, but not to HNF4 $\alpha$ knock-down; Category C, "Additive" contains genes whose expression is dependent on both treatments with cytokines and HNF4 $\alpha$ shRNA, and the effect of both treatments is additive, suggesting that the two treatments likely influence expression independent of each other. Finally, Category D, "Interactive" contains genes that exhibit an expression pattern dependent on both treatments in which the effect of the two treatments is not additive, rather interactive between each other. The genes with significantly altered expression and fold changes in each category are listed in Additional file 1. Utilizing K-means clustering, the genes in the category $\mathrm{A}$ and category B (Figure 2A and 2B) were clustered into 2 clusters for each category; Category $\mathrm{C}$ and category $\mathrm{D}$ (Figure $2 \mathrm{C}$ and $2 \mathrm{D}$ ) were clustered into 4 and 8 clusters, respectively.

As shown in Table 1, we identified a total of 5,173 probesets (36\% of the 14,220 probesets on the Affymetrix HG U133A 2.0 GeneChip with sequence-specific signal in our experiment) that exhibited differential expression in response to $\mathrm{HNF} 4 \alpha$ knock-down (false discovery rate, FDR $<0.01)$. Of these, 3,606 probesets were only affected by HNF $4 \alpha$ knock-down, and were not differentially expressed in response to cytokine stimulation (Category A). The remaining 1,567 probesets exhibited a differential expression pattern that was either specific to the combined effect of HNF4 $\alpha$ knock-down and cytokine treatments (502 probesets; Category D) or the genes that were affected by HNF4 $\alpha$ knock-down and cytokine treatments independently (1,065 probesets; Category C). Among the probesets affected by HNF4 $\alpha$ knock-down independently (Category A and Category C), many (3,088 of 4671 probesets) were up-regulated when HNF $4 \alpha$ expression was reduced. These observations may suggest that HNF4 $\alpha$ directly or indirectly regulates a large number of liver-specific gene expressions. We found that in our experimental conditions more genes appeared to be down-regulated or repressed under a normal level of HNF4 $\alpha$ in HepG2 cells. This finding is not in agreement with the description that HNF4 $\alpha$ functions primarily as a transcription activator $[8,30]$, but is more in line with the observation that HNF4 $\alpha$ can act as a suppressor of transcription [31,32]. To exclude an off-target effect of knock-down in our study, siRNA rescue experiments were performed. A rescue effect was observed in the knock-down HNF4 $\alpha$ HepG2 cells transfected with an HNF4 $\alpha$ siRNA-resistant construct generated by introducing silent substitutions in the HNF4 $\alpha$ siRNA-target region (Additional files 2 and 3). These siRNA rescue experiments suggest that the HNF4 $\alpha$ shRNA used in this study can specifically knock-down HNF4 $\alpha$ in HepG2 cells.

The observation that a large number of liver specific genes are affected by HNF $4 \alpha$ is consistent with the recent work of Odom et al. [13], in which the authors demonstrated that HNF $4 \alpha$ binds the promoters of $12 \%$ of genes in human liver cells, whereas HNF1 $\alpha$ binds the promoters of only $1.6 \%$ of genes using chromatin immunoprecipitation-chip (ChIP-chip). In order to determine what fraction of genes that showed differential expression in response to HNF4 $\alpha$ knock-down is likely to be bound by HNF4 $\alpha$, we compared our microarray expression data to the ChIP-chip data reported by Odom et al. Only those genes in the Odom's data for which there were probesets on our microarray were considered. We found that $54 \%$ (659 of 1,219) of the genes bound by HNF4 $\alpha$ detected by ChIP-chip also showed differential expression in response to HNF4 $\alpha$ knock-down on our microarray. A Fisher-Exact test was used to test whether the fraction of genes in the Odom et al. data that are differentially expressed in response to HNF4 $\alpha$ knockdown is significantly greater than the fraction of genes probed on our microarray that exhibit HNF4 $\alpha$-dependent expression, resulting in a highly significant $p$-value of $p=2.9 \times 10^{-33}$. A similar analysis determined that $13 \%\left(659 / 5,173, p=2.8 \times 10^{-17}\right)$ of those genes that exhibit differential expression in response to HNF4 $\alpha$ knock-down were reported by Odom et al. to be bound by $\mathrm{HNF} 4 \alpha$. These results suggest that a substantial fraction of HNF4 $\alpha$-sensitive genes may be indirect targets of HNF4 $\alpha$. However, the differences seen might also be caused by the significant differences in the experimental methods used such as the data from ChIP-chip were derived from human hepatocytes, while our experiment was performed on HepG2 cells.

\section{Majority of genes affected by cytokines are also affected by HNF4 $\alpha$ knock-down}

As shown in Table 2, we found that expression of $15 \%$ of the probesets $(2,202$ of 14,220) was affected by treatment with cytokine alone (635 probesets; Category B), 


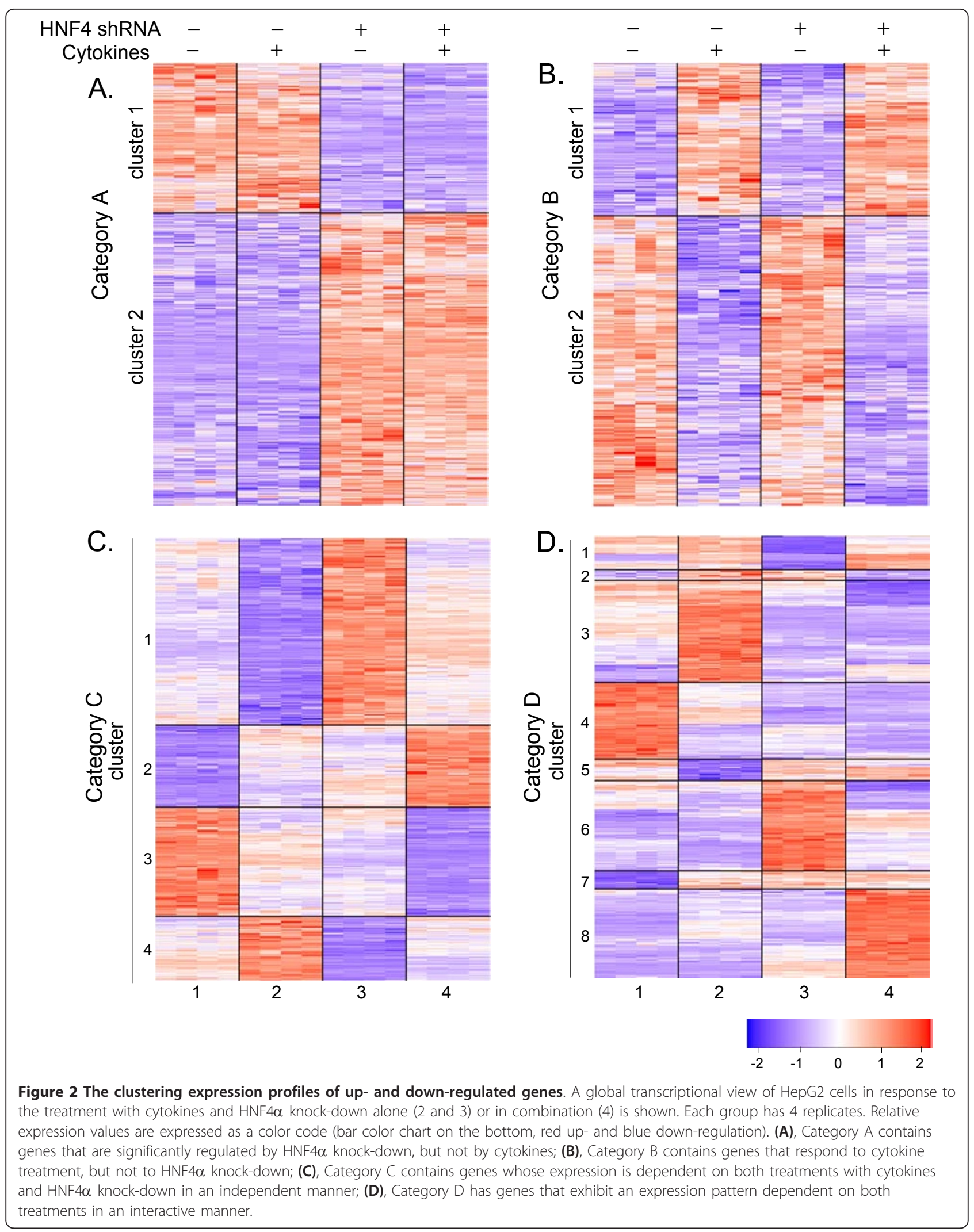


Table 1 Genes exhibiting altered expression by the treatment with HNF $4 \alpha$ shRNA alone and in combination with cytokines

\begin{tabular}{|c|c|c|c|c|c|}
\hline \multirow[t]{2}{*}{ Cut-off ${ }^{1}$} & \multirow[t]{2}{*}{ HNF4 shRNA only ${ }^{2}$} & \multicolumn{3}{|c|}{ HNF4 shRNA+Cytokines ${ }^{3}$} & \multirow[t]{2}{*}{ Tota } \\
\hline & & Additive & Interactive & Total & \\
\hline FDR $<0.01$ & 3606 & 1065 & 502 & 1567 & 517 \\
\hline 2-fold & 878 & 223 & 296 & 519 & 139 \\
\hline
\end{tabular}

Two methods of cut-off ${ }^{1}$, FDR (false discovery rate) and 2 -fold changes compared to untreated controls, are shown. HNF4 shRNA only ${ }^{2}$ (Category A) denotes that gene expressions are significantly changed by HNF $4 \alpha$ shRNA, but not by cytokines. HNF4 shRNA+Cytokines ${ }^{3}$ indicate that gene expressions are significantly changed by both HNF $4 \alpha$ shRNA and cytokines, including the additive (Category $\mathrm{C}$ ) and interactive (Category $\mathrm{D})$ effects.

and treatment with both HNF4 $\alpha$ shRNA and cytokines (1567 probesets; Category $\mathrm{C}$ and $\mathrm{D}$ ). Of the probesets that are differentially expressed in response to cytokine treatment but non-interactively with HNF4 $\alpha$ knockdown (Category $\mathrm{B}$ and $\mathrm{C}$ ) almost twice as many are down-regulated (1,144 probesets) as up-regulated (556 probesets). This may reflect that during the APR, there is an important role for the down-regulation of specific genes in response to an inflammatory stimulation, although the up-regulation of APR genes has been more extensively studied than those that are down-regulated.

More interestingly, we found that majority of those genes that exhibit differential expressions in response to cytokine treatment also reveal differential expression in response to HNF4 $\alpha$ knock-down. Of the 2,202 probesets found to be responsive to cytokine treatment, 1,567 (71\%) of them also show altered expression in response to knock-down of HNF4 $\alpha$, while only 635 probesets are not influenced by HNF4 $\alpha$ knock-down (Table 2). The $p$-value for this level of over-representation, calculated using a Fisher Exact test, is $1.8 \times 10^{-207}$. Some of these probesets are altered independently by cytokine treatment and reduction in HNF4 $\alpha$ levels (1,065 probesets; Category C), while others show a pattern of expression where the effect of cytokine treatment and reduction in HNF $4 \alpha$ levels is interdependent (502 probesets; Category $\mathrm{D})$. When more stringent criteria were used for filtering our data, and only those probesets in response to cytokine treatment and/or HNF4 $\alpha$ knock-down that change expression by more than two fold were chosen, we found that an even greater percentage (519/597, 87\%) of probesets regulated by cytokines are also regulated by HNF4 $\alpha$ (Table 2). This over-representation suggests that HNF4 $\alpha$ may play a significant role in orchestrating the inflammatory response in hepatic gene expression.

Although there is significant overlap between those probesets regulated by cytokines and those regulated by HNF4 $\alpha$ knock-down (Category C and D), the expression patterns in response to these two treatments are varied. For some probesets the response to HNF $4 \alpha$ knockdown are in the same direction as cytokine treatment
Table 2 Genes exhibiting altered expression by the treatment with cytokines alone and in combination with HNF4 $\alpha$ shRNA

\begin{tabular}{cccccc}
\hline \multirow{2}{*}{ Cut-off } & Cytokine only $^{\mathbf{1}}$ & \multicolumn{2}{c}{ HNF4 shRNA+Cytokines } & \multirow{2}{*}{ Total $^{\mathbf{2}}$} \\
\cline { 3 - 5 } & & Additive & Interactive & Total & \\
\hline FDR $<0.01$ & 635 & 1065 & 502 & 1567 & $\mathbf{2 2 0 2}$ \\
2-fold & 78 & 223 & 296 & 519 & $\mathbf{5 9 7}$ \\
\hline
\end{tabular}

Cytokine only ${ }^{1}$ (Category B) indicates that gene expressions are significantly changed by cytokines, but not by HNF4 $\alpha$ shRNA. HNF4 shRNA+Cytokines ${ }^{2}$ indicate that gene expressions are significantly changed by both HNF4 $\alpha$ shRNA and cytokines, including the additive (Category C) and interactive (Category D) effects.

(99 probesets, clusters 4 and 7 in the interactive category D, Figure 2D). This group of genes may represent a direct linkage of $\mathrm{HNF} 4 \alpha$ with the injury response and will serve as interesting targets for further study of the complex role of $\mathrm{HNF} 4 \alpha$ in the response to injury. For other genes the effect of each treatment is in opposition to each other (144 probesets, clusters 3 and 5 in Category D, Figure 2D). These diverse regulatory patterns observed suggest that the effects of HNF4 $\alpha$ knock-down as that of cytokine treatment are pleiotropic in nature affecting transcription events at basic levels allowing individual gene responses to be highly variable but none the less altered.

Previous work by our lab has demonstrated that HNF4 $\alpha$ binding activities are significantly reduced in a burn injury mouse model and a cytokine-induced APR cell culture model $[18,21]$. We have shown, utilizing the cell culture model, that the decrease in HNF4 $\alpha$ binding activity also affects HNF4 $\alpha$ 's ability to transactivate target genes [21]. The injury induced decrease in HNF4 $\alpha$ binding may affect cellular transcription by simply decreasing the amount of effective HNF4 $\alpha$ available for binding. Our ability to efficiently decrease HNF $4 \alpha$ concentration utilizing RNA interference technique may mimic this decrease in HNF4 $\alpha$ binding ability isolating this aspect of HNF4a's role in the injury response.

\section{Genes annotated as participating in inflammatory} response exhibit distinct expression patterns

In order to further explore the function of HNF $4 \alpha$ in the inflammatory response, a set of 170 genes annotated as playing a key role in inflammatory response was obtained from Gene ontology (GO) http://geneontology. org. These inflammatory response genes are highly enriched in the set of probesets up-regulated by cytokines ( $p=3.5 \times 10^{-3}, 334 \%$ above background), but not in those probesets down-regulated after cytokine treatment. Slightly more inflammatory response genes are up-regulated in response to HNF $4 \alpha$ knock-down than those that are down-regulated, but the difference is not statistically significant $(p>0.05)$. 
To determine whether certain expression patterns are associated with functional annotations, we further tested each cluster in each category using ANOVA analysis. While HNF4 $\alpha$-regulated probesets as a whole are not significantly enriched for the annotated inflammatory response genes, two expression clusters in the interactive category $\mathrm{D}$ are highly enriched for these genes. Of the 5,173 probesets regulated by HNF $4 \alpha$ knock-down, 25 of them are annotated as participating in inflammatory response, and 14 of these genes fall into one of two clusters. One of these clusters (cluster 8, Category D) contains 101 probesets that are dramatically up-regulated by the combination of HNF $4 \alpha$ shRNA and cytokine treatment, but exhibit relatively low levels of expression in the untreated controls, and the cells treated by either HNF4 $\alpha$ knock-down or cytokines alone. Nine of 101 probesets in cluster 8 are annotated in GO as participating in the inflammatory response, which is 8.2 times more than expected by chance $\left(p=2.2 \times 10^{-6}\right)$ (Figure 3A). Another cluster (cluster 1, Category D) contains 41 probesets expressed in moderate levels under all conditions except HNF4 $\alpha$ shRNA treatment in the absence of cytokines, in which they are markedly down-regulated. In this cluster, five genes are annotated as inflammatory response genes which is over 11.3 times more than expected by chance $\left(p=8.8 \times 10^{-5}\right)$ (Figure 3B). While it is not immediately clear why genes that play a role in inflammatory response are enriched in these particular expression clusters, it is intriguing that such genes exhibit similar HNF $4 \alpha$-dependent expression. These inflammatory response genes in cluster 8 and cluster 1 present good candidates for further study.

To confirm the microarray results, we chose several transcripts from category D, cluster 8 (C5 and LBP) and cluster 1 (SERPINA 3 and C4A), and measured their expressions with real-time PCR using the same RNA samples used for microarray studies. All of them showed a high concordance between microarray and real-time PCR data. Figure 4 illustrates the comparison of the expression levels between microarray (Figure 4A) and real-time PCR (Figure 4B) for the selected transcripts from cluster 8 and cluster 1 (Category D).

In addition to testing for enrichment of inflammatory response genes, enrichment for broad categories of functionality was calculated for each cluster. GO terms of all 26 top level biological processes were analyzed. We found that GO term of metabolism is significantly enriched in genes exhibiting HNF4 $\alpha$-dependent expression (Figure 5). As previous work [9,30,33] has noted that HNF4 $\alpha$ plays a significant role in regulating metabolism in the liver, it is not surprising that the GO term for metabolism is HNF4 $\alpha$-dependent. Thirty percent of genes $(1,530$ of 5,173$)$ that are differentially expressed in

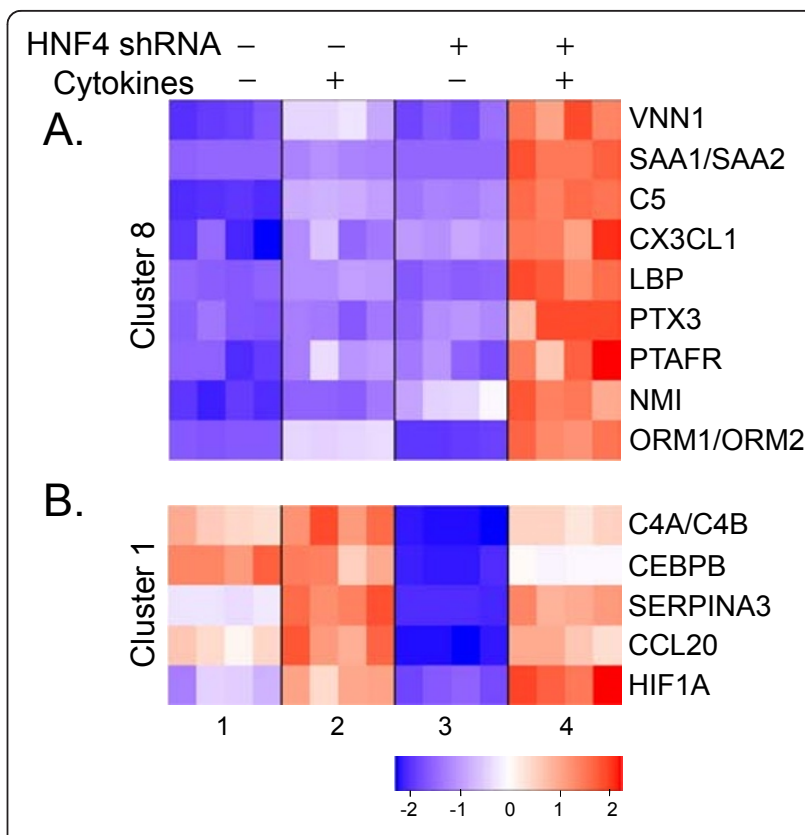

Figure 3 Inflammatory response genes are enriched in two clusters within the interactive category (Category D). Expression profiles of up- and down-regulated genes in the different groups treated by cytokines and HNF4 $\alpha$ knock-down alone (2 and 3) or in combination (4) are shown. Each group has 4 replicates. Relative expression values are expressed as a color code (bar color chart on the bottom, red up- and blue down-regulation). Inflammatory response genes (listed at the right side of the graph) extracted from $\mathrm{GO}$ are highly enriched in two different clusters (A and B). Gene abbreviations: VNN1, vanin 1; SAA1/SAA2, serum amyloid A1/serum amyloid A2; C5; complement component 5; CX3CL1, chemokine (CX3-C motif) ligand 1; LBP, lipopolysaccharide binding protein; PTX3, pentraxin-related gene, rapidly induced by IL-1 beta; PTAFR, plateletactivating factor receptor; NMI, N-myc (and STAT) interactor; ORM1/ ORM2, orosomucoid 1/orosomucoid 2; C4A/C4B, complement component 4A/complement component 4B; CEBPB, CCAAT/ enhancer binding protein (C/EBP), beta; SERPINA3, serpin peptidase inhibitor, clade A (alpha-1 antiproteinase, antitrypsin), member 3; CCL20, chemokine (C-C motif) ligand 20; HIF1A, hypoxia-inducible factor 1, alpha subunit (basic helix-loop-helix transcription factor).

response to HNF4 $\alpha$ knock-down are annotated as participating in a metabolic process, resulting in a Fisher Exact $p$-value of $2.6 \times 10^{-18}$.

\section{HNF $4 \alpha$ may regulate a large number of targets via the ETS family of transcription factors}

To gain insight into the complex transcriptional networks that regulate hepatic gene expression, the promoter region $(-1 \mathrm{~kb}$ to $+0.5 \mathrm{~kb}$ relative to the transcription start site, TSS) of genes was extracted, and potential transcription factor binding sites were identified using Clover [34]. By extensive search of the genes found to be differentially expressed as a function of HNF $4 \alpha$ knock-down, we found that the HNF4 $\alpha$ motif is not statistically enriched in the promoters of genes whose expression changes in response to HNF4 $\alpha$ knock-down 


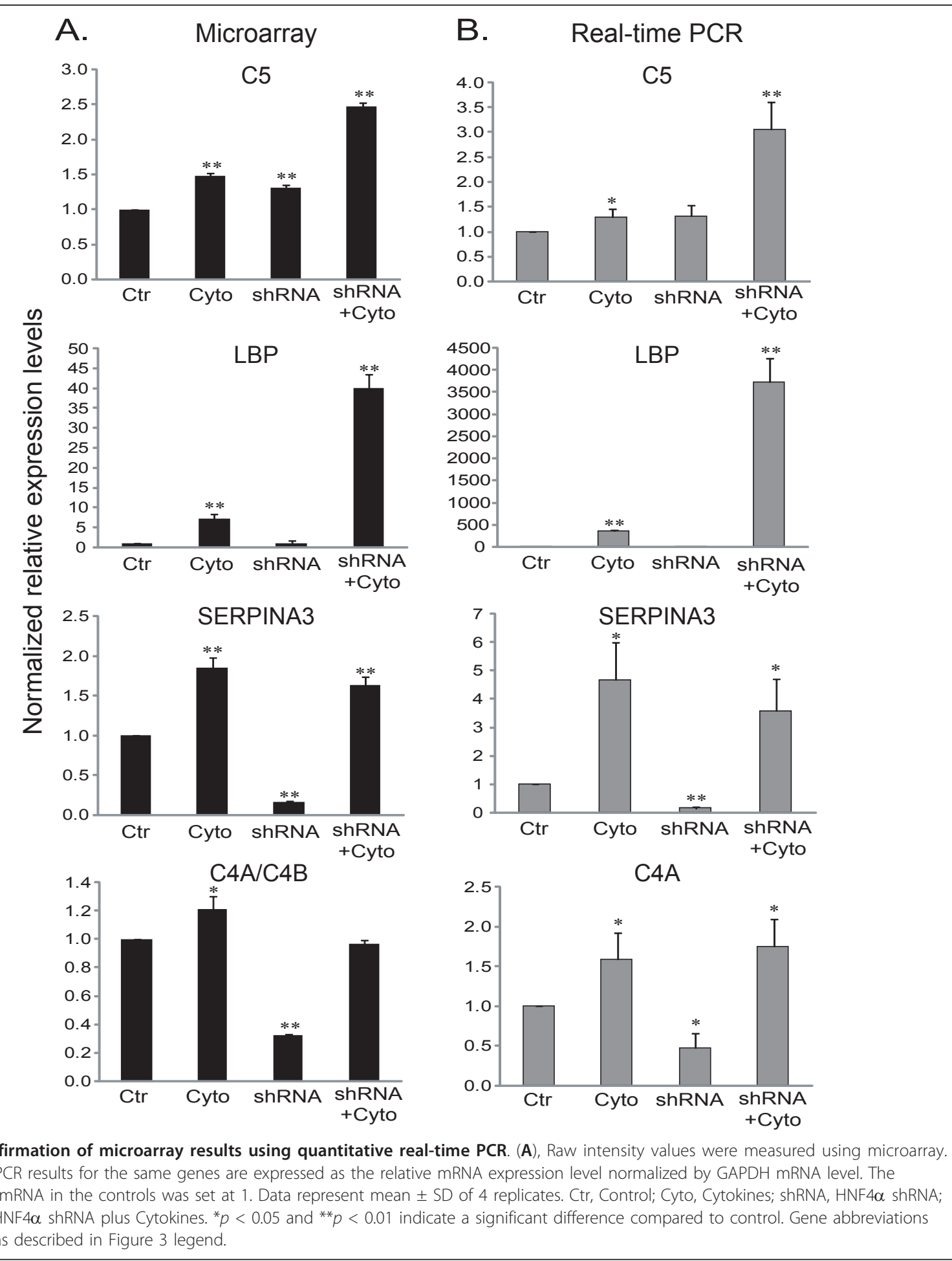

relative to promoters chosen randomly from throughout the genome $(p>0.05)$. There are several possible reasons for this observation. Firstly, HNF4 $\alpha$ binding sites may be located far up-stream or down-stream of the TSS, although the results still remain the same when we extended our search up to $5 \mathrm{~kb}$ up-stream and $2.5 \mathrm{~kb}$ down-stream of the TSS. Secondly, there might be a fraction of sites that bind HNF4 $\alpha$ but differ from the established consensus. Thirdly, HNF4 $\alpha$ may interact with proximal promoters through formation of enhancer/promoter loops with HNF4 $\alpha$ binding to distal regulatory element [35]. Yet another possibility is that 


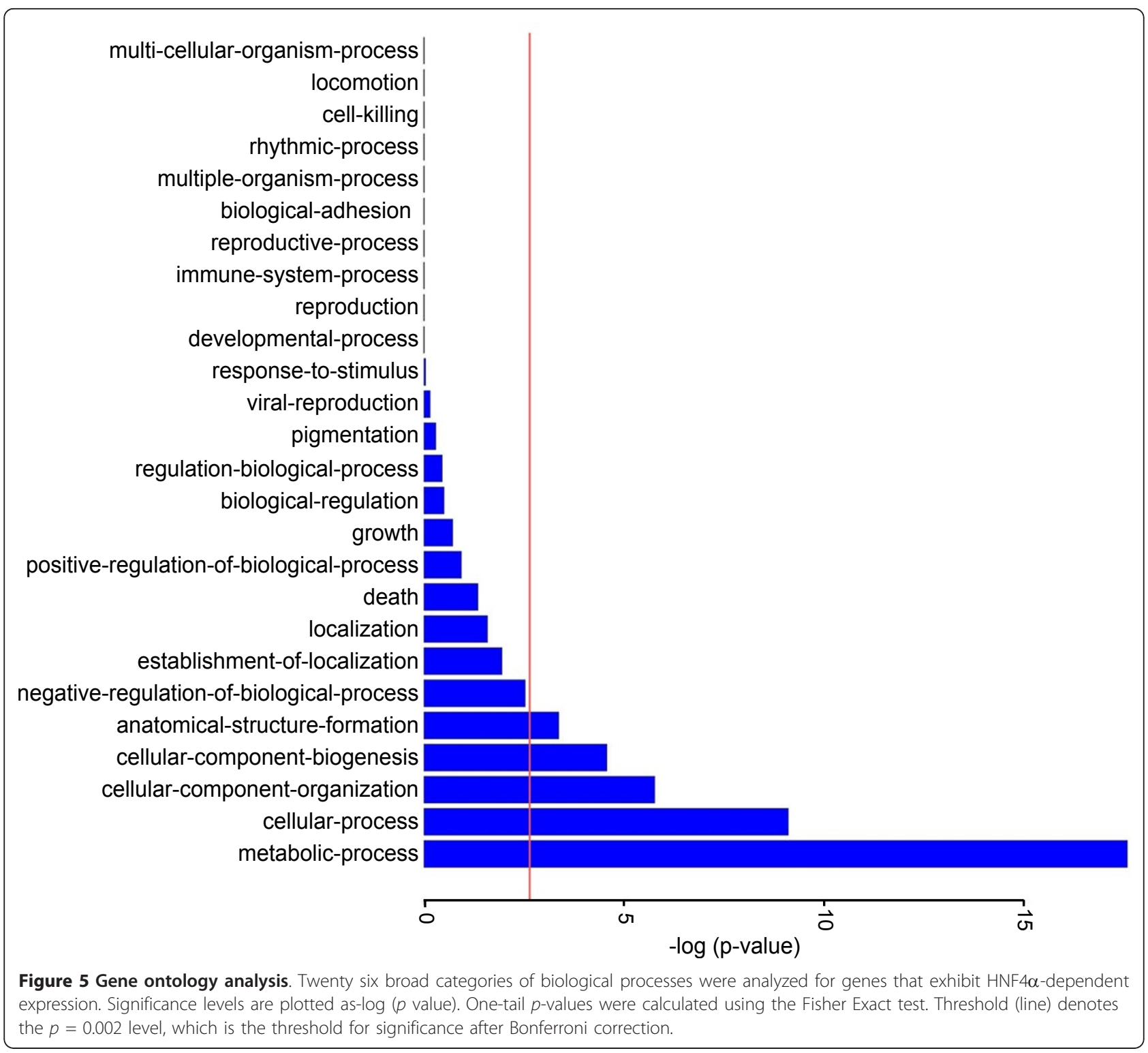

HNF4 $\alpha$ might act as a cofactor, interacting with other transcription factors and not directly bind to DNA.

Indeed, we found that the binding sites for the ETS family of transcription factors including ELK1, ELK4 and GA binding protein transcription factor A (GABPA) are highly enriched in the HNF4 $\alpha$ knock-down group. The binding motifs for ELK1 $\left(p=4.0 \times 10^{-7}\right)$, ELK4 $(p=1.14 \times$ $\left.10^{-10}\right)$ and GABPA $\left(p=3.4 \times 10^{-5}\right)$ are very similar (Figure $6)$, and all significantly enriched in the promoter regions of genes affected by HNF $4 \alpha$ knock-down. This mirrors a finding by Smith et al. [36], where they showed that ELK1 binding motifs are enriched in the promoters of genes also bound by HNF4 $\alpha$. Moreover, in this study we found that ELK1 and ELK4 genes exhibit significant differential expression in response to HNF4 $\alpha$ knock-down. ELK1 is up-regulated when HNF4 $\alpha$ is knocked down, while ELK4 is down-regulated. These results suggest that HNF4 $\alpha$ may regulate a substantial number of genes via ELK transcription factors.

The transcription factor ELK1 is of particular interest as this protein is a nuclear target of extracellular-regulated kinases (ERKs) and plays a pivotal role in immediate early gene induction by external stimuli $[28,29]$. It has been known that HNF4 $\alpha$ expression is modulated by MAP kinase signaling [37,38]. Li et al. [39] reported that ELK1 is involved in the inflammatory response via stimulation of chemokine by thrombin. These observations suggest that the relationship between ELK1 and HNF4 $\alpha$ may be especially relevant to understanding the role of HNF4 $\alpha$ in regulating the inflammatory response.

By searching for ELK1 binding site in the HNF4 $\alpha$ regulated genes (5173 genes), we identified 373 genes 
that have one or more potential ELK1 binding sites in their promoter regions $(-1 \mathrm{~kb}$ to $+0.5 \mathrm{~kb})$ (Additional file 4). To define a functional link between HNF4 $\alpha$ and ELK1, we selected 4 genes (COL4A1, ZNF175, MMP15 and SEC24A). These genes all were found having an ELK1 binding motif (CCGGAAG/A, Figure 6), but no HNF $4 \alpha$ binding motif in their proximal promoter regions, and from our microarray analysis their expressions were shown to be either up-regulated (COL4A1, ZNF175) or down-regulated (MMP15 and SEC24A) by HNF4 $\alpha$ knock-down. The expression of these potential ELK1 target genes was examined by real-time PCR in HepG2 cells treated with siRNA to knock-down HNF4 $\alpha$ and/or ELK1 alone or both together. As shown in Figure 7, the expression of ELK1 can be efficiently knockeddown by siRNA. The knock-down of HNF4 $\alpha$ resulted in a significantly greater ELK1 expression compared to control $(p<0.05)$, and the ELK1 expression was not significantly affected by cytokine treatment, which are consistent with our microarray data. We propose that HNF $4 \alpha$ may indirectly regulate a number of genes through ELK1 transcription factor based on the observation that the ELK1 binding site is highly enriched in genes affected by HNF4 $\alpha$ knock-down. It was predicted that if a higher ELK1 expression induced by HNF4 $\alpha$ knock-down affects the transcriptional outcomes of ELK1-target genes, we should see an opposite regulatory effect on these gene transcriptions when the ELK1 level is reduced. The results (Figure 8) show that when the cells were treated with siELK1 either alone or with siHNF4 $\alpha$, the two genes up-regulated by HNF4 $\alpha$ knockdown (Figures $8 \mathrm{~A}$ and $8 \mathrm{~B}$ ) are expressed at significantly lower levels compared to HNF4 $\alpha$ knocked-down $(p<$ $0.01)$. In contrast, the genes down-regulated by HNF4 $\alpha$ knock-down (Figures 8C and 8D) show significantly increased expression compared to siHNF4 $\alpha(p<0.01)$. This result is consistent with a direct effect of ELK1 level induced by the decrease of HNF $4 \alpha$ concentration on a subset of ELK1-target genes. However, these findings could be explained by another mechanism by which an HNF4a/ELK1 complex is formed, leading to alterations in the regulation of a group of genes. To test this hypothesis, chromatin immunoprecipitation (ChIP) assays were performed. An HNF4 $\alpha$ antibody was used to immunoprecipitate chromatin from HepG2 cells. Specific PCR primers were utilized to amplify a DNA fragment with an ELK1 binding motif, and without an HNF4 $\alpha$ binding motif. As shown in Figure 9, HNF4 $\alpha$ was able to interact with these genes containing ELK1 binding sites, and the interactive ability of HNF4 $\alpha$ was significantly reduced after the knock-down of ELK1. Interestingly, when the HNF4 $\alpha$ binding motif was further searched using a web-based search tool, HNF4 Motif Finder [40], a potential HNF4 binding site was
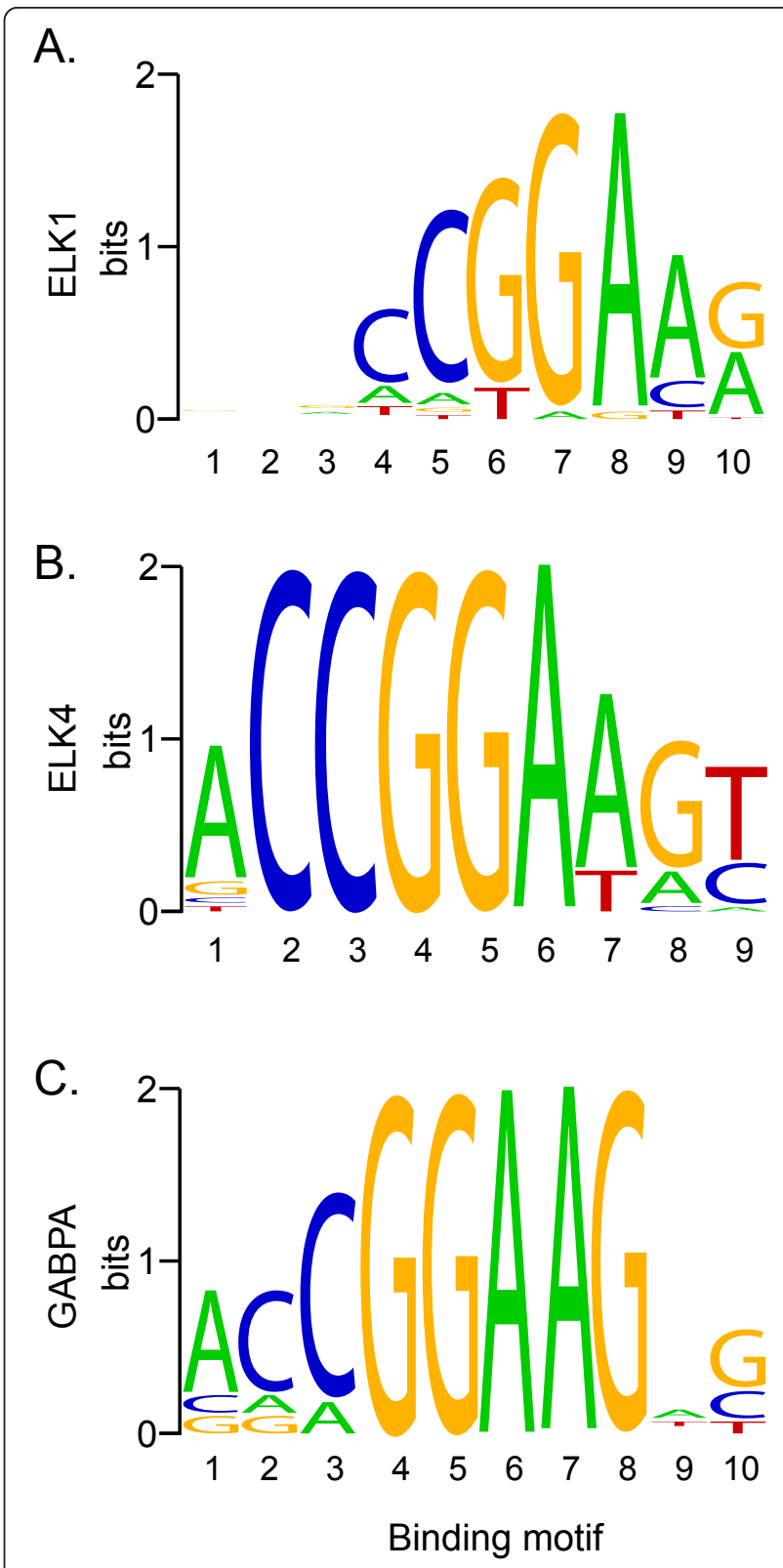

Figure 6 Sequence logos of ETS transcription factor binding sites. Sequence logos of consensus DNA binding sites for the three ETS transcription factors enriched in genes regulated by HNF $4 \alpha$. Y axis indicates amount of information at each position in the motif. These logos were generated from information obtained from the JASPAR core database [42]. (A), ELK1 binding motif; (B), ELK4 binding motif; and (C), GABPA binding motif.

identified in the promoter region of MMP15, which could lead to a direct binding of HNF4 $\alpha$ when HNF4 $\alpha$ antibody was used to immunoprecipitate chromatin. However, if HNF4 $\alpha$ binding to MMP15 is independent of ELK1, when ELK1 is knocked down, one would expect to see no change in the binding of MMP15 in the ChIP assay, this is not the case as shown in Figure 9. Furthermore, we found that ELK1 can directly bind 


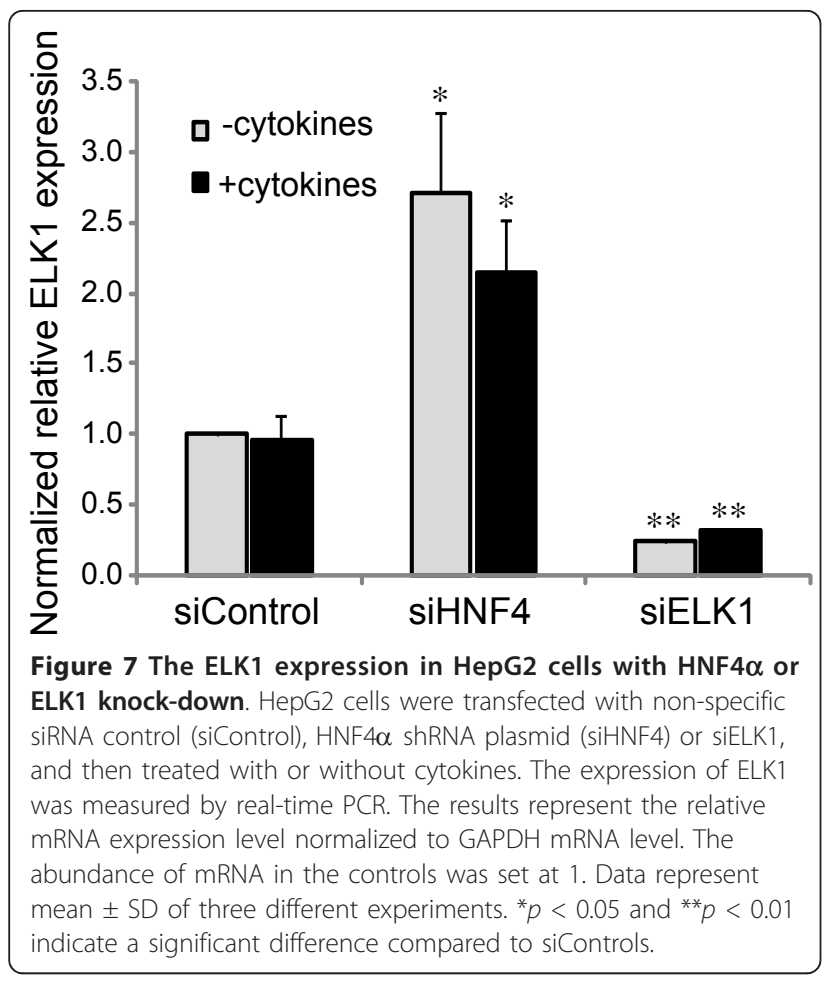

to its potential ELK1 binding site in MMP15 utilizing electrophoretic mobility shift analysis (data not shown). Given these findings, we hypothesize that HNF4 $\alpha$ may indirectly mediate gene expression, in part, through a co-operative interaction with ELK1, and possibly also with other ETS transcription factors. Others have reported that a number of ETS family proteins interact and crosstalk with several transcription factors including AP-1, NF- $\kappa$ B and Stat -5 to co-regulate the expression of cell-type specific genes. Such interactions coordinate cellular processes in response to diverse signals including cytokines, growth factors, antigen and cellular stresses [41], here we believe that we have uncovered a novel interplay between the transcription factors HNF $4 \alpha$ and ELK1 for controlling gene expression in the liver.

\section{Conclusions}

$\mathrm{HNF} 4 \alpha$ is a major regulator of hepatic gene expression. The complex physiological effects of HNF4 $\alpha$ on the regulation and maintenance of hepatic phenotype are likely involved both directly and indirectly in a systemic response such as that seen in a response to injury or inflammation. Our microarray data are consistent with a broad effect of HNF $4 \alpha$ on liver functions, and more importantly, the microarray analysis provides a genomic view for the role of $H N F 4 \alpha$ in the inflammation response, which greatly extends the observations from both animal- and cell culture-injury models. However, more experimentation and a focus on individual pathways will need to be done before a full picture of HNF-4 $\alpha$ 's role in the modulation of hepatic phenotype by injury can be obtained.

\section{Methods}

\section{Cell culture and treatments}

HepG2 cells (ATCC \# HB-8065), human hepatoma cells, were grown in Dulbecco Modified Eagle Medium (DMEM) supplemented with penicillin (100 units/ml), streptomycin $(100 \mu \mathrm{g} / \mathrm{ml})$, and $10 \%$ heat-inactivated fetal bovine serum (Mediatech, Herndon, VA) at $37^{\circ} \mathrm{C}$ in a humidified atmosphere with $5 \% \mathrm{CO}_{2}$.

The inflammatory response in HepG2 cells was stimulated with a cytokine mixture consisting of $1 \mathrm{ng} / \mathrm{ml}$ of recombinant human IL-1 $\beta, 10 \mathrm{ng} / \mathrm{ml}$ of IL-6, and $10 \mathrm{ng} /$ $\mathrm{ml}$ of TNF- $\alpha$ (PeproTech, Rocky Hill, NJ) in serum-free medium for $18 \mathrm{~h}$.

Knock-down of HNF4 $\alpha$ in HepG2 cells was carried out as described previously [21]. Briefly, shRNA plasmids (HNF4 $\alpha$ shRNA and non-specific control shRNA) were transfected into HepG2 cells with the Nucleofector (Amaxa Biosystem, Cologne, Germany) T-28 protocol following the manufacturer's instructions. Knock-down of ELK1 in HepG2 cells was performed by transfection with small interfering RNA (siRNA) (Ambion, Austin, TX) using lipofectamine 2000 reagent (Invitrogen, Carlsbad, CA) according to the manufacturer's instructions. Twenty-four hours after transfection, the cells were placed in serum-free medium for $5 \mathrm{~h}$ and then either treated or untreated with cytokines for $18 \mathrm{~h}$.

The different treated HepG2 cells were divided into four groups: Group 1, control: the cells were transfected with non-specific control shRNA; Group 2, HNF4 $\alpha$ shRNA: the cells were transfected with HNF4 $\alpha$ shRNA; Group 3, cytokines: the control cells were transfected with non-specific control shRNA and then treated with cytokines; Group 4, HNF4 $\alpha$ shRNA with cytokine treatment: the cells were transfected with HNF4 $\alpha$ shRNA prior to the treatment with cytokines. Four biological replicates from separate experiments were performed for each of the four study groups.

\section{Total RNA isolation and real-time PCR}

Total RNA was extracted using the RNeasy Mini Kit (Qiagen, Valencia, CA) according to the manufacturer's instructions. Quantitative real-time PCR analysis was conducted on the ABI 7000 Sequence Detection System and StepOnePlus ${ }^{\mathrm{TM}}$ Real-Time PCR System. Relative mRNA expression was quantified using the comparative Ct $(\Delta \Delta \mathrm{Ct})$ method according to the ABI manual (Applied Biosystems, Foster City, CA). Amplification of glyceraldehyde-3-phosphate dehydrogenase (GAPDH) was used in each reaction as an internal reference gene. Assays were performed in triplicate. TaqMan probes were used for the human HNF4 $\alpha$ (Hs00230853_m1), 


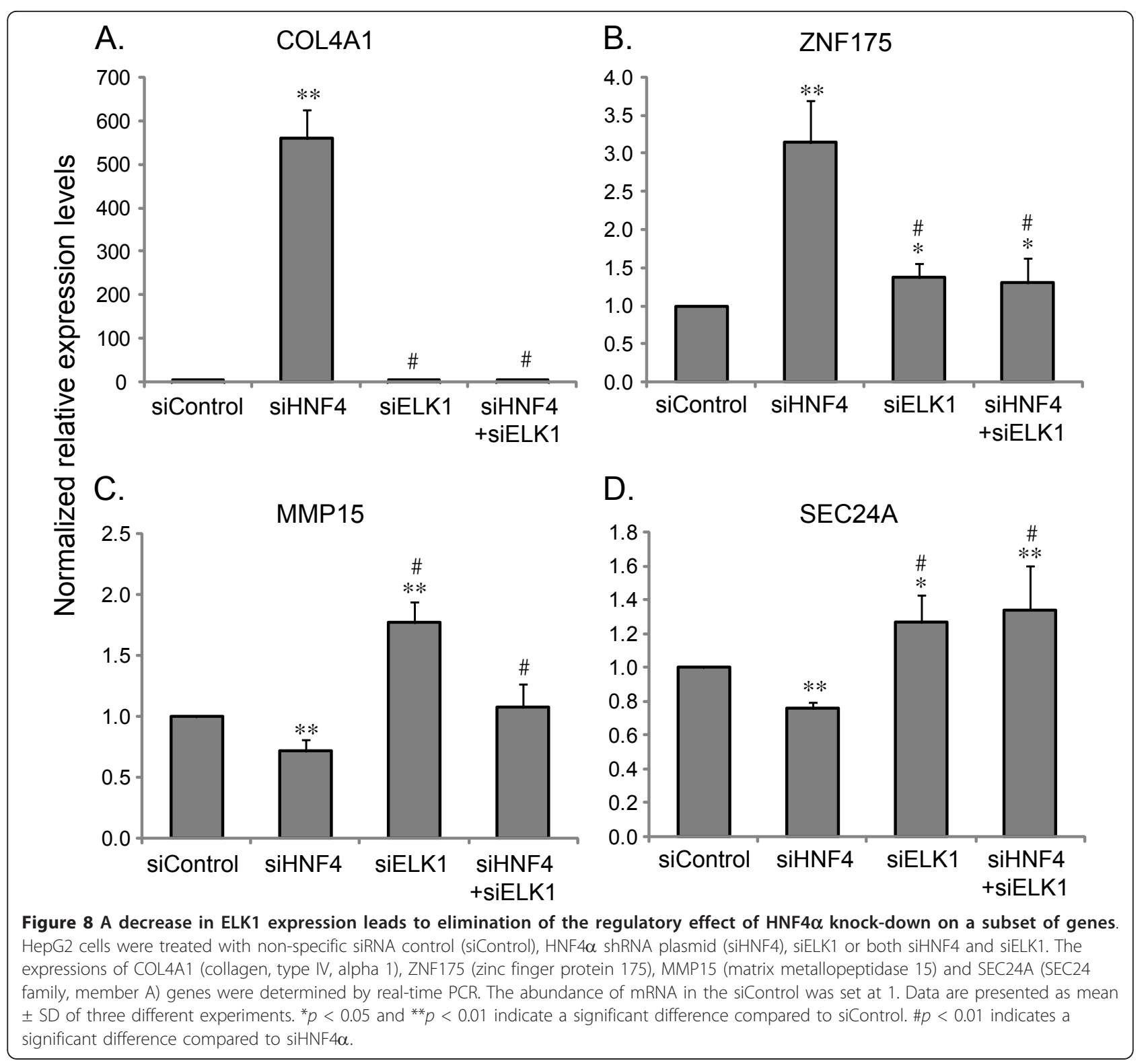

complement component 5 (C5, Hs00156197_m1), lipopolysaccharide binding protein (LBP, Hs00188074_m1), serpin peptidase inhibitor member 3 (SERPINA3, Hs00153674_m1), complement component 4A (C4A, Hs00167147_m1), ELK1 (Hs00901847_m1), collagen, type IV, alpha 1 (COL4A1, Hs01007469_m1), zinc finger protein 175 (ZNF175, Hs00232535_m1), matrix metallopeptidase 15 (MMP15, Hs00233997_m1), SEC24 family, member A (SEC24A, Hs00405228_m1) and GAPDH (Hs99999905_m1) from the TaqMan ${ }^{\circledR}$ Gene Expression Assays (Applied Biosystems).

\section{Microarray analysis}

Affymetrix HG-U133A 2.0 GeneChips were used to study the expression levels for HepG2 cell RNA. Sample labeling, hybridization to microarrays, scanning and calculation of normalized expression levels were carried out at the Microarray Resource, Boston University School of Medicine, Boston, MA. RNA samples (four biological replicates for each of the four study groups: control, HNF4 $\alpha$ shRNA, cytokines, and HNF4 $\alpha$ shRNA with cytokine treatment) were analyzed. Microarray data were quantified and normalized using Affymetrix MicroArray Suite (MAS) 5.0. Two-way ANOVA analysis was then used to determine which probesets were differentially expressed between the untreated control and treated groups. Only probesets exhibiting differential expression with FDR $<0.01$ were included in this study. After the ANOVA analysis was performed, K-means clustering was then used to cluster probesets that 


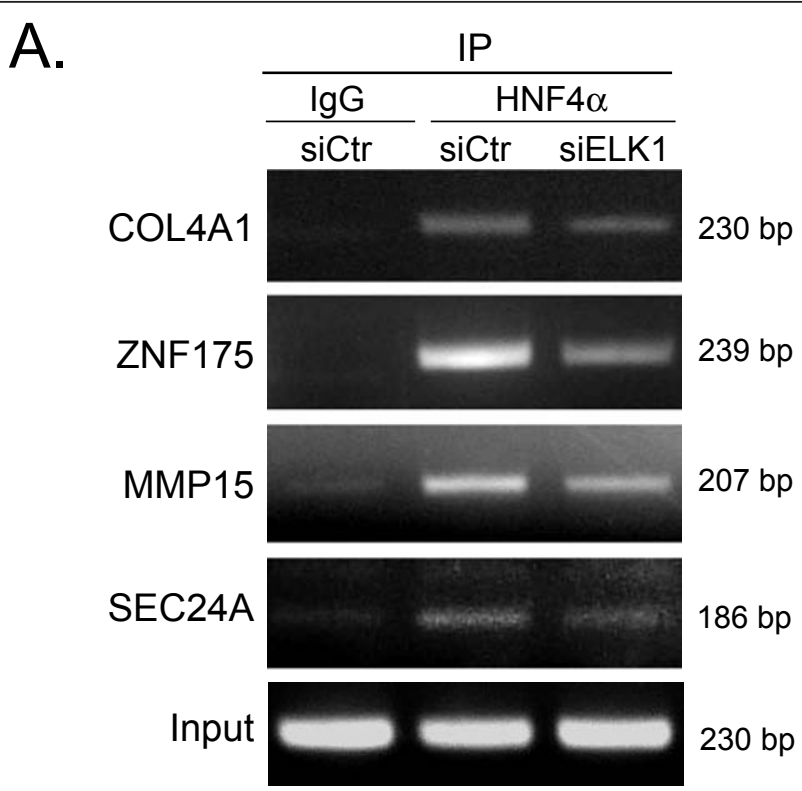

\section{B.}

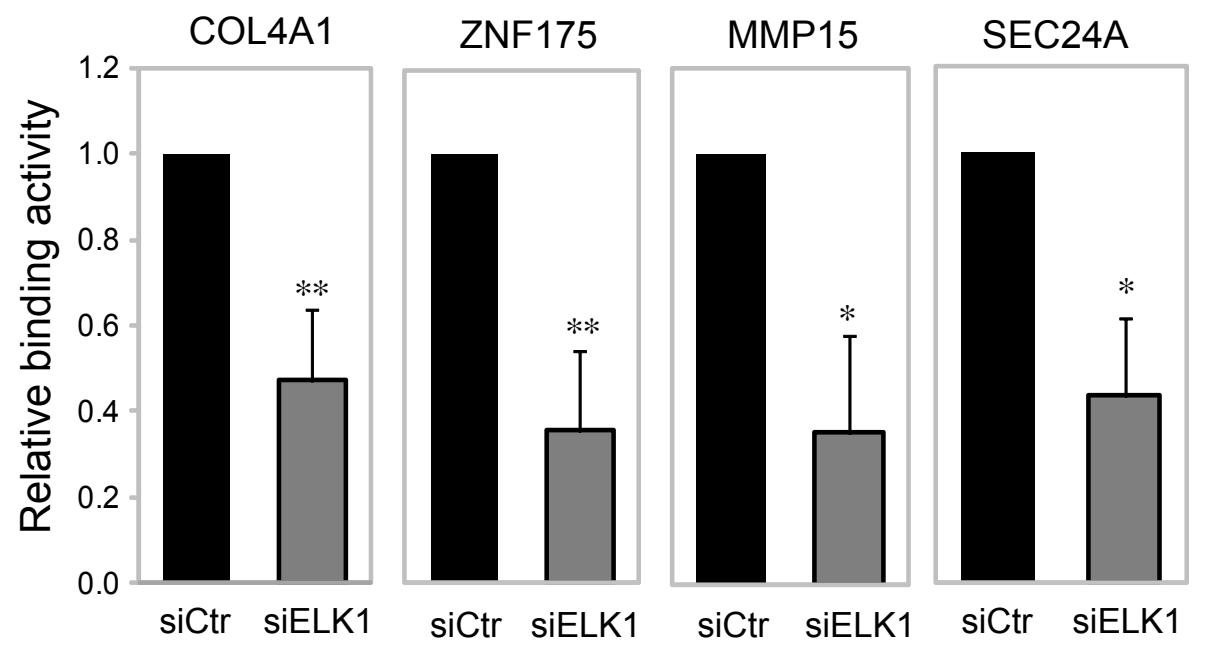

Figure 9 The reduction of ELK1 level decreases the ability of HNF4 $\alpha$ to interact with the promoters of a subset of genes. (A), HepG2 cells were transfected with siControl (siCtr) or siELK1. Protein interaction of HNF4 $\alpha$ and ELK1 was determined by ChIP assay with either antibody against HNF4 $\alpha$ or goat normal $\operatorname{lgG}(\mathrm{IgG}$ ). Chromatin-immunoprecipitated DNA was analyzed by PCR with primers specific for the ELK1 binding sites in the promoter regions of COL4A1, ZNF175, MMP15 and SEC24A genes. The result shown in (A) is a representative experiment, replicated three times with similar results. (B), Histograms show densitometric analyses of relative binding abilities. Values represent mean \pm SD of three separate experiments. The relative quantitative analysis was carried out by comparison of siELK1 with siControl, and the siControl was set at 1. ${ }^{*} p<0.05$ and ${ }^{* *} p<0.01$ indicate a significant difference compared to siCtr. IP, immunoprecipitation.

exhibit similar expression patterns within each category of differential expression. In order to eliminate multiple probesets, the raw data were clustered based on Unigene identifiers (ids), which represent unique transcription loci. Unigene ids associated with multiple probesets that exhibit different patterns of expression were removed from the dataset, ensuring unambiguous data that could be easily used in subsequent enrichment analyses. This approach ensures that, if anything, the results of subsequent analyses are conservative.

\section{Gene ontology (GO) enrichment analysis}

Before GO enrichment could be calculated, each GO annotation was mapped to a corresponding Unigene id. 
SwissProt ids associated with each Unigene id were obtained and were used for this purpose. Where SwissProt ids were not available, gene symbols were used to associate GO annotations with Unigene ids. Each cluster in all 4 categories was then tested for enrichment for genes associated with inflammatory response GO database (relative to the entire set of genes on the microarray) using Fisher's Exact test. In addition, to identify other functionality, each cluster was tested for enrichment of each of the top-level "biological process" annotations in the GO database. As there are 26 top-level "biological process", a Bonferroni correction was applied for this top-level analysis, resulting in a $p$-value cut-off of 0.002 .

\section{Promoter analysis}

Weight matrices obtained from the JASPAR core database [42] were used to identify potential transcription factor binding sites in the up-stream of promoter regions. One promoter with each Unigene id was included in the analysis, so that genes with multiple annotated promoters/TSS did not bias the analysis. The region, extending from $-1 \mathrm{~kb}$ to $+0.5 \mathrm{~kb}$ relative to the TSS, was extracted. Clover [34] was used with a minimum log-ratio score cut-off of 8.0 to identify potential binding sites in this region. Promoters were classified based on whether they contain at least one binding site, and enrichment in different expression clusters relative to a background set of promoters derived from all probesets present on the microarray. The randomization feature of Clover was not used, instead the exact number of promoters containing binding sites in both the HNF4 $\alpha$-regulated set and the background set were computed, and a $p$-value was calculated using Fisher's Exact test. Because there are almost 140 transcription factors in the JASPAR database, a Bonferroni correction was applied, resulting in a $p$-value cut-off of $3.5 \times 10^{-4}$.

\section{Chromatin immunoprecipitation (ChIP) assay}

ChIP assay was performed as described previously [21]. The purified chromatin was immunoprecipitated using $10 \mu \mathrm{g}$ of anti-HNF-4 $\alpha$ (sc-6556, Santa Cruz Biotechnology, Santa Cruz, CA) or normal goat IgG (Santa Cruz). After DNA purification, the presence of the ELK1 putative binding motif (CCGGAAG/A) DNA sequence was assessed by PCR. The primers used were as follows: (1) COL4A1 gene: 5'-GAGTTTAGCGCAGGATGAGG-3' and 5'-GCTCTCCTGCTTGGGAGTAG-3', and the PCR product is $230 \mathrm{bp}$ in length; (2) ZNF175: 5'-TAAAAGC CCTTTGACGATGG-3' and 5'-CTCTAGGCCACTT CCGGTTT-3', and the PCR product is 239 bp in length; (3) MMP15: 5'-ATCCAGCTCGTTAAGCTTCG-3' and 5'-TTAATCTCTCCGAGCCTCCA-3' for amplifying a 207 bp DNA fragment. (4) SEC24A: 5'-GCACCAGGA
GCTGTCAGG-3' and 5'-GGCAGCCAAACCTAGAG AGA-3', and the PCR product is $186 \mathrm{bp}$ in length. The PCR conditions were as following: $95^{\circ} \mathrm{C}$ for $10 \mathrm{~min}$, followed by $94^{\circ} \mathrm{C}$ for $45 \mathrm{~s}, 58^{\circ} \mathrm{C}$ for $60 \mathrm{~s}$, and $72^{\circ} \mathrm{C}$ for $60 \mathrm{~s}$ for a total of 31 cycles. In the ELK1 knock-down experiments, the relative quantitative analysis in binding activity was performed, utilizing densitometry and statistical analysis, by comparison of siELK1 with non-specific siRNA control, and the control was set at 1 .

\section{Additional material}

Additional file 1: Genes that respond to the treatment of HNF4 $\alpha$

knock-down and/or cytokines. This file includes four sub-tables

showing the genes with significantly altered expression and fold changes in four categories (Category A to D).

Additional file 2: Construction of HNF4 $\alpha$ siRNA-resistant mutant. This file illustrates the generation and DNA sequencing of the HNF $4 \alpha$ siRNA-resistant construct.

Additional file 3: siRNA rescue assay. This file shows the characterization of the HNF $4 \alpha$ siRNA-resistant construct by Western blot, and the rescue effect of this construct on HNF $4 \alpha$ knock-down responsive genes.

Additional file 4: ELK1 and HNF4 $\alpha$ binding motifs in HNF4 $\alpha$ regulated genes. This file shows the sequence and position of ELK1 and HNF $4 \alpha$ potential binding sites in the group of HNF $4 \alpha$-regulated genes.

\section{Acknowledgements}

This work was supported by NIH grant (R01DK064945). The authors wish to thank the Microarray Resource, Boston University School of Medicine, Boston, MA for performing the microarray experiments and for help with data analysis. We also thank Dr. Marc Lenburg and Dr. Avrum Spira for critical reading of the manuscript.

\section{Author details}

${ }^{1}$ Department of Surgery, Boston University School of Medicine, Boston, Massachusetts 02118, USA. ${ }^{2}$ Bioinformatics Graduate Program, Boston University, Boston, Massachusetts 02215, USA.

\section{Authors' contributions}

$Z W$ and PAB designed the experiment. ZW performed the experiments. EPB analyzed the data. ZW and EPB wrote the manuscript. All authors read and approved the final manuscript.

Received: 1 March 2010 Accepted: 25 February 2011

Published: 25 February 2011

\section{References}

1. Costa RH, Kalinichenko W, Holterman AX, Wang X: Transcription factors in liver development, differentiation, and regeneration. Hepatology 2003, 38(6):1331-1347.

2. Wiwi CA, Waxman DJ: Role of hepatocyte nuclear factors in growth hormone-regulated, sexually dimorphic expression of liver cytochromes P450. Growth Factors 2004, 22(2):79-88.

3. Cheung C, Akiyama TE, Kudo G, Gonzalez FJ: Hepatic expression of cytochrome P450 s in hepatocyte nuclear factor 1-alpha (HNF1alpha)deficient mice. Biochem Pharmacol 2003, 66(10):2011-2020.

4. Clotman F, Lannoy VJ, Reber M, Cereghini S, Cassiman D, Jacquemin P, Roskams T, Rousseau GG, Lemaigre FP: The onecut transcription factor HNF6 is required for normal development of the biliary tract. Development 2002, 129(8):1819-1828.

5. Shih DQ, Navas MA, Kuwajima S, Duncan SA, Stoffel M: Impaired glucose homeostasis and neonatal mortality in hepatocyte nuclear factor 3alphadeficient mice. Proc Natl Acad Sci USA 1999, 96(18):10152-10157. 
6. Wang ND, Finegold MJ, Bradley A, Ou CN, Abdelsayed SV, Wilde MD, Taylor LR, Wilson DR, Darlington GJ: Impaired energy homeostasis in C/ EBP alpha knockout mice. Science 1995, 269(5227):1108-1112.

7. Chen WS, Manova K, Weinstein DC, Duncan SA, Plump AS, Prezioso VR, Bachvarova RF, Darnell JE Jr: Disruption of the HNF-4 gene, expressed in visceral endoderm, leads to cell death in embryonic ectoderm and impaired gastrulation of mouse embryos. Genes Dev 1994, 8(20):2466-2477.

8. Hayhurst GP, Lee YH, Lambert G, Ward JM, Gonzalez FJ: Hepatocyte nuclear factor 4alpha (nuclear receptor 2A1) is essential for maintenance of hepatic gene expression and lipid homeostasis. Mol Cell Biol 2001, 21(4):1393-1403.

9. Hanniman EA, Lambert G, Inoue Y, Gonzalez FJ, Sinal CJ: Apolipoprotein AIV is regulated by nutritional and metabolic stress: involvement of glucocorticoids, HNF-4 alpha, and PGC-1 alpha. J Lipid Res 2006, 47(11):2503-2514.

10. Inoue $Y$, Yu AM, Yim SH, Ma X, Krausz KW, Inoue J, Xiang CC, Brownstein MJ, Eggertsen G, Bjorkhem I, et al: Regulation of bile acid biosynthesis by hepatocyte nuclear factor 4alpha. J Lipid Res 2006, 47(1):215-227.

11. Miura A, Yamagata K, Kakei M, Hatakeyama H, Takahashi N, Fukui K, Nammo T, Yoneda K, Inoue Y, Sladek FM, et al: Hepatocyte nuclear factor4alpha is essential for glucose-stimulated insulin secretion by pancreatic beta-cells. J Biol Chem 2006, 281(8):5246-5257.

12. Ryffel GU: Mutations in the human genes encoding the transcription factors of the hepatocyte nuclear factor (HNF)1 and HNF4 families: functional and pathological consequences. J Mol Endocrinol 2001 27(1):11-29.

13. Odom DT, Zizlsperger N, Gordon DB, Bell GW, Rinaldi NJ, Murray HL, Volkert TL, Schreiber J, Rolfe PA, Gifford DK, et al: Control of pancreas and liver gene expression by HNF transcription factors. Science 2004, 303(5662):1378-1381.

14. Baumann H, Gauldie J: The acute phase response. Immunol Today 1994, 15(2):74-80.

15. Beal AL, Cerra FB: Multiple organ failure syndrome in the $1990 \mathrm{~s}$. Systemic inflammatory response and organ dysfunction. Jama 1994, 271(3):226-233.

16. Cerra FB: The systemic septic response: concepts of pathogenesis. Trauma 1990, 30(12 Suppl):S169-174.

17. Herbst RS, Nielsch U, Sladek F, Lai E, Babiss LE, Darnell JE Jr: Differential regulation of hepatocyte-enriched transcription factors explains changes in albumin and transthyretin gene expression among hepatoma cells. New Biol 1991, 3(3):289-296.

18. Li X, Salisbury-Rowswell J, Murdock AD, Forse RA, Burke PA: Hepatocyte nuclear factor 4 response to injury involves a rapid decrease in DNA binding and transactivation via a JAK2 signal transduction pathway. Biochem J 2002, 368(Pt 1):203-211.

19. Burke PA, Drotar M, Luo M, Yaffe M, Forse RA: Rapid modulation of liverspecific transcription factors after injury. Surgery 1994, 116(2):285-292, discussion 292-283.

20. Burke PA, Luo M, Zhu J, Yaffe MB, Forse RA: Injury induces rapid changes in hepatocyte nuclear factor-1: DNA binding. Surgery 1996, 120(2):374-380, discussion 380-371.

21. Wang Z, Burke PA: Effects of hepatocyte nuclear factor-4alpha on the regulation of the hepatic acute phase response. J Mol Biol 2007, 371(2):323-335.

22. Perlmutter $\mathrm{DH}$, May LT, Sehgal PB: Interferon beta 2/interleukin 6 modulates synthesis of alpha 1-antitrypsin in human mononuclear phagocytes and in human hepatoma cells. J Clin Invest 1989, 84(1):138-144

23. Knowles BB, Howe CC, Aden DP: Human hepatocellular carcinoma cell lines secrete the major plasma proteins and hepatitis B surface antigen. Science 1980, 209(4455):497-499.

24. Ganapathi MK, May LT, Schultz D, Brabenec A, Weinstein J, Sehgal PB, Kushner I: Role of interleukin-6 in regulating synthesis of C-reactive protein and serum amyloid $\mathrm{A}$ in human hepatoma cell lines. Biochem Biophys Res Commun 1988, 157(1):271-277.

25. Bartalena L, Farsetti A, Flink IL, Robbins J: Effects of interleukin-6 on the expression of thyroid hormone-binding protein genes in cultured human hepatoblastoma-derived (Hep G2) cells. Mol Endocrinol 1992 6(6):935-942.
26. Baumann H, Richards C, Gauldie J: Interaction among hepatocytestimulating factors, interleukin 1, and glucocorticoids for regulation of acute phase plasma proteins in human hepatoma (HepG2) cells. J Immunol 1987, 139(12):4122-4128.

27. Gauldie J, Richards C, Harnish D, Lansdorp P, Baumann H: Interferon beta 2/B-cell stimulatory factor type 2 shares identity with monocyte-derived hepatocyte-stimulating factor and regulates the major acute phase protein response in liver cells. Proc Natl Acad Sci USA 1987, 84(20):7251-7255

28. Shaw PE, Saxton J: Ternary complex factors: prime nuclear targets for mitogen-activated protein kinases. Int J Biochem Cell Biol 2003, 35(8):1210-1226

29. Sharrocks AD: Complexities in ETS-domain transcription factor function and regulation: lessons from the TCF (ternary complex factor) subfamily. The Colworth Medal Lecture. Biochem Soc Trans 2002, 30(2):1-9.

30. Naiki T, Nagaki M, Shidoji Y, Kojima H, Imose M, Kato T, Ohishi N, Yagi K, Moriwaki H: Analysis of gene expression profile induced by hepatocyte nuclear factor 4alpha in hepatoma cells using an oligonucleotide microarray. J Biol Chem 2002, 277(16):14011-14019.

31. Stanulovic VS, Kyrmizi I, Kruithof-de Julio M, Hoogenkamp M, Vermeulen JL, Ruijter JM, Talianidis I, Hakvoort TB, Lamers WH: Hepatic HNF4alpha deficiency induces periportal expression of glutamine synthetase and other pericentral enzymes. Hepatology 2007, 45(2):433-444.

32. Rodriguez JC, Ortiz JA, Hegardt FG, Haro D: The hepatocyte nuclear factor 4 (HNF-4) represses the mitochondrial HMG-CoA synthase gene. Biochem Biophys Res Commun 1998, 242(3):692-696

33. Sladek FM, Zhong WM, Lai E, Darnell JE Jr: Liver-enriched transcription factor HNF-4 is a novel member of the steroid hormone receptor superfamily. Genes Dev 1990, 4(12B):2353-2365.

34. Frith MC, Fu Y, Yu L, Chen JF, Hansen U, Weng Z: Detection of functional DNA motifs via statistical over-representation. Nucleic Acids Res 2004, 32(4):1372-1381

35. Rada-Iglesias A, Wallerman O, Koch C, Ameur A, Enroth S, Clelland G, Wester K, Wilcox S, Dovey OM, Ellis PD, et al: Binding sites for metabolic disease related transcription factors inferred at base pair resolution by chromatin immunoprecipitation and genomic microarrays. Hum Mol Genet 2005, 14(22):3435-3447.

36. Smith AD, Sumazin P, Das D, Zhang MQ: Mining ChIP-chip data for transcription factor and cofactor binding sites. Bioinformatics 2005, 21(Suppl 1):i403-412.

37. Reddy S, Yang W, Taylor DG, Shen X, Oxender D, Kust G, Leff T: Mitogenactivated protein kinase regulates transcription of the ApoCIII gene. Involvement of the orphan nuclear receptor HNF4. J Biol Chem 1999, 274(46):33050-33056.

38. Hatzis P, Kyrmizi I, Talianidis I: Mitogen-activated protein kinase-mediated disruption of enhancer-promoter communication inhibits hepatocyte nuclear factor 4alpha expression. Mol Cell Biol 2006, 26(19):7017-7029.

39. Li QJ, Vaingankar S, Sladek FM, Martins-Green M: Novel nuclear target for thrombin: activation of the Elk1 transcription factor leads to chemokine gene expression. Blood 2000, 96(12):3696-3706.

40. Bolotin E, Liao H, Ta TC, Yang C, Hwang-Verslues W, Evans JR, Jiang T, Sladek FM: Integrated approach for the identification of human hepatocyte nuclear factor 4alpha target genes using protein binding microarrays. Hepatology 2010, 51(2):642-653

41. Li R, Pei H, Watson DK: Regulation of Ets function by protein-protein interactions. Oncogene 2000, 19(55):6514-6523.

42. Sandelin A, Alkema W, Engstrom P, Wasserman WW, Lenhard B: JASPAR: an open-access database for eukaryotic transcription factor binding profiles. Nucleic Acids Res 2004, 32 Database: D91-94.

doi:10.1186/1471-2164-12-128

Cite this article as: Wang et al:: Expression profile analysis of the inflammatory response regulated by hepatocyte nuclear factor $4 \alpha$. BMC Genomics 2011 12:128. 